\title{
LA VERDADERA IDENTIDAD DE ENRIQUE DE LA PLUTT, AGENTE AL SERVICIO DEL II MARQUÉS DE CASTEL RODRIGO
}

\author{
DAVID GARCÍA CUETO \\ Universidad de Granada
}

\begin{abstract}
La biografía de Manuel de Faria y Sousa, antiguo criado del II marqués de Castel Rodrigo, desvela algunos aspectos desconocidos de la identidad de Enrique de la Plutt, personaje al que el marqués encomendó supervisar en Roma la realización del conocido ciclo de paisajes para el Buen Retiro.

Palabras clave: Enrique de la Plutt; Manuel de Moura y Corte Real; II marqués de Castel Rodrigo; Manuel de Faria y Sousa; Roma; Buen Retiro (Madrid); siglo XVII.
\end{abstract}

\section{THE TRUE IDENTITY OF ENRIQUE DE LA PLUTT, AGENT IN THE SERVICE OF THE II MARQUÉS DE CASTEL RODRIGO}

The biography of Manuel de Faria y Sousa, a former servant of the II Marquis of Castel Rodrigo, reveals unknown aspects of the identity of Enrique de la Plutt, the person entrusted by the Marquis to supervise the realization in Rome of the well-known cycle of landscape paintings for the Buen Retiro palace.

Key words: Enrique de la Plutt; Manuel de Moura y Corte Real; II Marquis of Castel Rodrigo; Manuel de Faria y Sousa; Rome; Buen Retiro (Madrid); $17^{\text {th }}$ century.

Es un hecho bien conocido cómo a lo largo de la década de 1630 llegaron a Madrid desde Italia un enorme número de pinturas destinadas a adornar el recién inaugurado real palacio del Buen Retiro. El estado actual de las investigaciones permite afirmar que aquella gran operación de compra de obras de arte a algunos de los más importantes pintores por entonces activos en Italia fue el resultado de la acción conjunta de dos relevantes diplomáticos, el virrey de Nápoles conde de Monterrey y el embajador en Roma marqués de Castel Rodrigo, quienes siguieron un programa de encargos y adquisiciones diseñado y dirigido desde Madrid por el conde-duque de Olivares, como recientemente ha podido confirmar con nuevos documentos Mercedes Simal ${ }^{1}$.

Entre Roma y Nápoles, con artistas originarios de ambas ciudades o residentes en ellas, se realizaron varias series de importantes pinturas, entre las que se contaba una dedicada a la Roma antigua, otra a la vida de San Juan Bautista y un amplio ciclo de más de veinte paisajes con santos y anacoretas. Las dos primeras series las encargó el conde de Monterrey, bien directamente a artistas residentes en Nápoles, bien a algunos que vivían en Roma, valiéndose en el caso de estos últimos del agente Juan Rubio de Herrera ${ }^{2}$. En la Ciudad Eterna, don Manuel de Moura y Corte Real, II marqués de Castel Rodrigo y embajador de Felipe IV ante la Santa Sede entre los años 1632 y $1642^{3}$, se ocupó de la realización de la conocida serie de paisajes con santos y anacoretas, "el más amplio y articulado encargo europeo de pintura de paisajes del siglo XVII" en palabras de Giovanna Capitelli, sirviéndose como intermediario del flamenco Enrique Van Vluete, de la Flur, de la Fluete o de la Plutt ${ }^{4}$. Para ello contó con unas instrucciones muy someras que le fueron enviadas desde Madrid, habiéndose iniciado la ejecución de las pinturas en Roma antes de mayo de $1633^{5}$.

A De la Plutt se le ha considerado, a la vista de diversas evidencias documentales, como un agente flamenco reclutado expresamente por el marqués de Castel Rodrigo para coordinar el

\footnotetext{
${ }^{1}$ Simal LóPeZ, Archivo Español de Arte, 335, 2011: 245-260.

2 Sobre las pinturas encargadas por Monterrey, véase ÚBEDA DE LOS CoBOs, 2005: 169-240.

3 García Cueto, 2007: 695-716.

${ }^{4}$ Constan todas estas grafías de su apellido y aún otras más en los documentos de la época. Véase al respecto CAPITELLI, 2005: 241-284. Ha actualizado la cuestión ÚBEDA DE LOS CoBos: 2011: 79-90.

5 Simal LóPeZ, Archivo Español de Arte, 335, 2011: 247-248.
} 


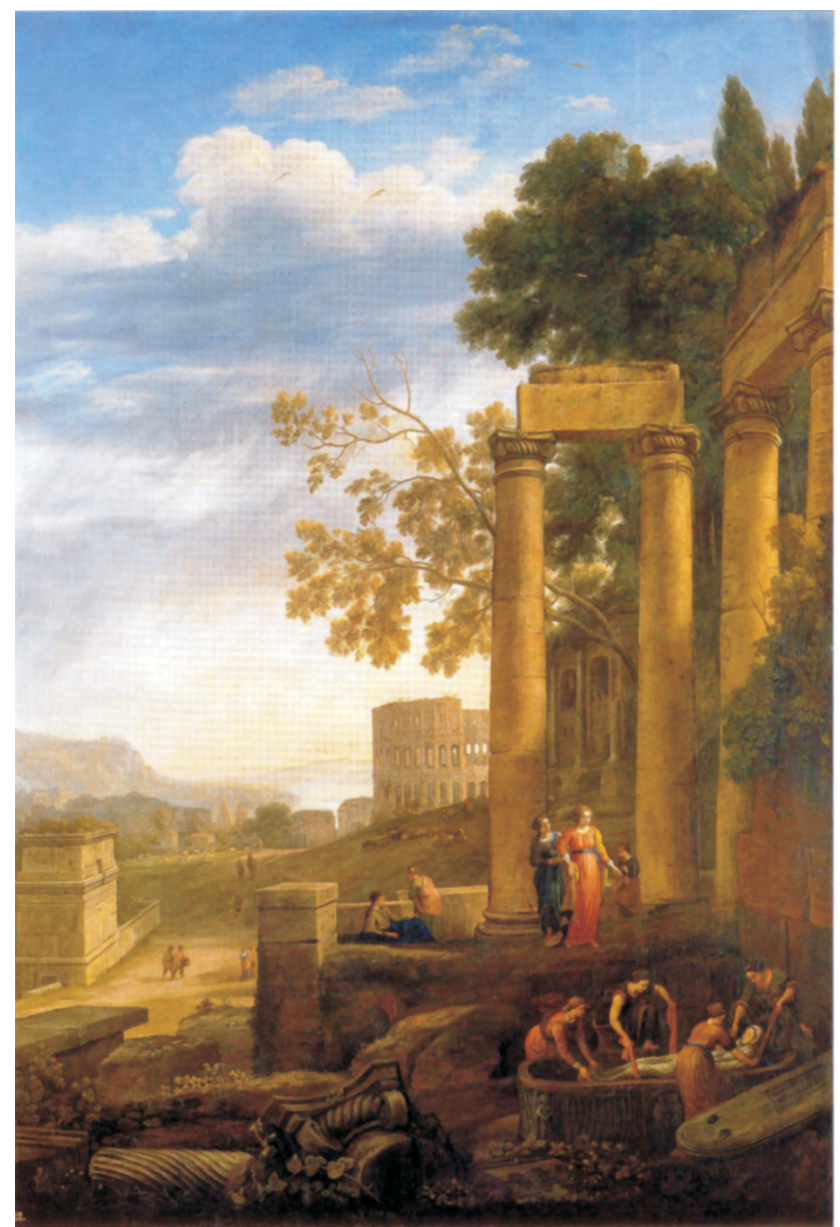

Fig. 1. Claudio de Lorena, Paisaje con el entierro de Santa Serapia, Madrid, Museo del Prado. Una de las pinturas encargadas por Castel Rodrigo en Roma para el Buen Retiro.

encargo de los paisajes en Roma. Gracias a las averiguaciones de Alessandra Anselmi, consta que era originario de la ciudad flamenca de Brujas, y que en 1633, residiendo ya en Roma, se declaraba familiaris et continuus commensalis del marqués de Castel Rodrigo ${ }^{6}$. Tal consideración habría de ser interpretada, en el contexto de la época, como que De la Plutt era uno de los miembros del séquito del marqués de Castel Rodrigo más cercanos al propio aristócrata. A la vista de los registros de la población de Roma que cada año se realizaban, parece probable que fuese así, pudiendo encontrarse entre la "familia" o séquito del marqués que habitaba junto a él en el palacio de la embajada en la Plaza de España a un hombre con su mismo nombre?

\footnotetext{
${ }^{6}$ AnSELmi, 2000: 112.

7 Archivio Storico del Vicariato, Roma (ASVR), Fondo Parrocchiale, Sant'Andrea delle Fratte, Stato delle anime 1629-1634. Año de 1634, fols. 310r- 312r. Los noventa y siete servidores del marqués son recordados sólo por sus nombres propios, encontrándose entre ellos a un tal "Errigo", seguramente Enrique de la Plutt.
} 
El papel desempeñado por De la Plutt en la satisfacción del encargo regio fue fundamental, pues no sólo se ocupó personalmente de seguir la realización de las pinturas en Roma, sino también de su transporte a Madrid en al menos dos viajes, uno a finales de $1638^{8}$ y otro en noviembre de $1640^{9}$. Hubo probablemente un tercer envío de las pinturas encargadas por Castel Rodrigo en 1641, aunque se desconoce si De la Plutt también estuvo implicado en el mismo ${ }^{10}$. El trato intenso que necesariamente mantuvo con los pintores paisajistas asentados en Roma ${ }^{11}$ debió de hacer que De la Plutt se convirtiese en alguien familiar en el mundo del arte en la capital pontificia. Tal circunstancia facilitaría que además de ocuparse de la coordinación del encargo de pinturas para la corona, De la Plutt satisficiera al menos desde 1636 otras peticiones de índole semejante que le llegaron de otros aristócratas españoles con intereses en Italia, como el duque de Alcalá, que era cuñado de Castel Rodrigo, o el duque de Medina de las Torres ${ }^{12}$. Parece por tanto razonable pensar que el flamenco contaba con una apreciable especialización en cuestiones artísticas, si bien es posible afirmar ahora que tal condición no la poseía previamente a coordinar el encargo de paisajes para el Buen Retiro, sino que más bien la adquirió mientras realizó tal tarea.

La consideración de una fuente coetánea y extremadamente rica en informaciones relativas a la biografía del II marqués de Castel Rodrigo permite ahora afirmar que Enrique de la Plutt era uno de los pajes que el aristócrata había llevado consigo en su séquito desde Madrid, y no un agente especializado en asuntos artísticos que estuviese previamente establecido en Roma. El literato portugués Manuel de Faria Sousa, que sirvió al marqués de Castel Rodrigo hasta su irreconciliable ruptura con el aristócrata en 1634 -y que por tanto le acompañó en los primeros años de su embajada en Roma-, dejó noticias de primera mano sobre Enrique de la Plutt en su autobiografía, editada por Edward Glaser en $1975^{13}$. En aquel relato autobiográfico, Faria Sousa descargó todo el odio que había acumulado a lo largo de los años hacia el marqués, a quien retrata como un hombre de conducta mezquina y arbitraria, desvelando una faceta del todo diversa a la del aristócrata piadoso y moderado que las fuentes más conocidas parecen transmitir.

Recuerda Faria en un pasaje de esta obra suya que "en Madrid había el marqués aceptado, entre otros, a un mozo flamenco cuyo nombre era Enrique de la Flur, y luego empezó a tratar con él con tanta particularidad que ofendía a todos los que en ello reparaban"14. Siempre según Faria, Enrique de la Plutt había vivido en Roma antes de ser admitido por el marqués como paje en Madrid, llegando incluso a ordenarse jesuita, pero hubo de colgar los hábitos "por saberse de él un cierto vicio". Al parecer, tales antecedentes no se descubrieron hasta que Castel Rodrigo con todo su séquito -incluido el flamenco- se encontraba ya en Génova, camino de la corte romana para iniciar su embajada. La noticia llegó por una vía autorizada, pues fue el prestigioso jesuita residente en Roma Nuño de Mascareñas, tío de Castel Rodrigo y representante de la rama portuguesa de la orden, quien le informó sobre el pasado del paje. El respetable jesuita aconsejó a su sobrino que no llevase a Roma a De la Plutt, pero el marqués no sólo desoyó tal recomendación, sino que "tratóle como antes y no digo con más estrechez porque no podía ser"15. Tal

${ }^{8}$ Dado a conocer por BRown y ElLIOTt, 1987: 104.

9 La llegada del agente con las pinturas la recuerda AzCÁRATE, 1966: 125.

10 Simal López, 2011: 249.

11 Una relevante carta publicada por ANSELMI, 2000: 11, relativa al proceso de realización de las pinturas para el Buen Retiro, recuerda cómo en 1640 casi todos los pintores de Roma "lavorano per ordine di esso D. Henrique per serv[izi]o di S[ua] M[aestà]”. Carta de Theodosio Enríquez a Niccolò Ludovisi, príncipe de Piombino.

12 Simal LóPez, 2011: 249-250.

13 GLASER, 1975: p. 242.

14 GLASER, 1975: p. 242

15 Glaser, 1975: p. 242: "Este mozo [De la Plutt] había estado en Roma y tomado el hábito de la Compañía de Jesús y dejándolo por saberse de él un cierto vicio; pero esto último no se supo sino en Génova, y el saberse procedió 
cercanía del paje al marqués era cuestión de habladurías, pudiendo constatarse aquella familiaridad en un episodio concreto que Faria Sousa presenció. Un violento enfrentamiento que De la Plutt tuvo con otro criado de Castel Rodrigo, un tal Martín de Arana, fue la excusa perfecta para que el aristócrata se librase de éste último, manteniendo en cambio al flamenco a su servicio ${ }^{16}$.

Aquellos rumores de un trato en exceso estrecho, inapropiado entre un criado con antecedentes dudosos y su señor, seguramente no tardaron en llegar a Madrid. Allí, los enemigos políticos de Castel Rodrigo, entre los que se contaba el propio conde-duque de Olivares, supieron sacar partido a tales habladurías. En 1634 se inició en la corte española un humillante proceso secreto contra el marqués, pesando sobre él la acusación de sodomía ${ }^{17}$. En flamenco De la Plutt habría sido, como el contexto hace pensar, el supuesto compañero de pecado del marqués. Pero el transcurso de aquel proceso legal no parece que afectara al trato entre Castel Rodrigo y De la Plutt, quienes como se ha visto desarrollaron una fructífera colaboración al servicio de la corona en los años siguientes.

Aunque el aristócrata quedó exento de cualquier condena, el daño que el proceso haría a su reputación hubo de ser más que considerable. Tras el fin de su embajada romana, acelerado por la declaración de independencia del reino de Portugal -de donde Castel Rodrigo era originarioFelipe IV le encomendó un nuevo destino lejos de Madrid, en la Dieta de Ratisbona. Nada se sabe por el momento sobre el destino de De la Plutt después de 1641, aunque es de suponer que el proceso legal marcaría duramente su biografía. Pero más allá de lo anecdótico, las noticias aquí expuestas sirven para encuadrar mejor la personalidad del hombre al que se encomendó el extraordinario encargo de los paisajes solicitados a Castel Rodrigo por la corona. Enrique de la Plutt, tras formarse como jesuita en Roma, hubo de poseer una considerable cultura general y el pleno dominio de las lenguas italiana y latina, así como amplios conocimientos de Historia Sagrada y hagiografía. Sabría también desenvolverse en la vida cotidiana de la Urbe y conocería algo de los entresijos de su mundo artístico. Parece por tanto que al igual que Juan Rubio de Herrera y otros agentes españoles presentes en Roma durante el siglo XVII, el flamenco Enrique de la Plutt fue un individuo hábil y con cierta formación al que las circunstancias convirtieron en un buen conocedor de los asuntos artísticos.

\section{BIBLIOGRAFÍA}

Anselmi, Alessandra, “Arte, politica e diplomazia: Tiziano, Correggio, Raffaello, l'investitura del Piombino e notizie su agenti spagnoli a Roma”, en Cropper, Elisabeth (dir.), The Diplomacy of Art. Artistic Creation and Politics in Seicento Italy, Milán, 2000, pp. 101-120.

Azcárate, José María de, "Anales para la construcción del Buen Retiro", Anales del Instituto de Estudios Madrileños, 1, 1966, pp. 99-135.

\footnotetext{
de haberlo escrito al marqués su tío Nuño de Mascareñas, religioso de la propia Compañía, que allá era asistente por la de Portugal, viejo de autoridad. Parecióle a este varón circunspecto que el marqués llevaría su casa compuesta de hombres bien morigerados, y como él sabía que aquel mozo no lo era y que el traerle consigo procedía de no tener información de sus costumbres, decíale en la carta que convenía a su crédito no llevarle a Roma, y que allá a boca le diría las causas. Si le escribiera en su favor no le hallara más ventajoso; tratóle como antes y no digo con más estrechez porque no podía ser".

16 Glaser, 1975: 308: “Andando los marqueses con deseo de echar de sí a Martín de Arana [uno de sus criados], sucedió que él acuchilló con infame cobardía a Enrique de la Flur, aquel mozo flamenco estimado del marqués, que de esto se hizo motivo para echarle, poniendo miedo con que el herido le había de matar".

17 MARTíneZ HeRnÁNDEZ, 2012.
} 
Brown, Jonathan y Elliott, John, "The Marquis of Castel Rodrigo and the Landscape Paintings in the Buen Retiro", The Burlington Magazine, 127, 1987, pp. 191-192.

Capitelli, Giovanna, "Los paisajes para el palacio del Buen Retiro", en El Palacio del Rey Planeta. Felipe IV y el Buen Retiro, cat. exp., Madrid, Museo del Prado, 2005, pp. 241-284.

García Cueto, David, "Mecenazgo y representación del marqués de Castel Rodrigo durante su embajada en Roma”, en Hernando Sánchez, Carlos (coord.), Roma y España. Un crisol de la cultura europea en la Edad Moderna, Madrid, 2007, vol. II, pp. 695-716.

Glaser, Edward (editor), The "Fortuna” of Manuel de Faria e Sousa. An Autobiography, Münster, 1975.

Martínez Hernández, Santiago, "Oposición aristocrática y anti-olivarismo: el proceso secreto contra el marqués de Castel Rodrigo, embajador de Felipe IV en Roma (1634)", Actas del congreso internacional La Corte en Europa: Política y Religión (siglos XVI-XVIII), Madrid, 2012, vol. II, pp. 1147-1196.

Simal López, Mercedes, "Nuevas noticias sobre las pinturas para el Real Palacio del Buen Retiro realizadas en Italia (1633-1642)”, Archivo Español de Arte, 335, 2011, pp. 245-260.

Úbeda de los Cobos, Andrés, "El ciclo de la Historia de Roma antigua", en El Palacio del Rey Planeta. Felipe IV y el Buen Retiro, cat. exp., Madrid, Museo del Prado, 2005, pp. 169-240.

Úbeda de los Cobos, Andrés, "Las pinturas de paisaje para el palacio del Buen Retiro", en Roma, naturaleza e ideal. Paisajes, 1600-1650, cat. exp., Madrid, Museo del Prado, 2011, pp. 79-90. 